\title{
From The Traditional Radio to Podcast or To the À La Carte
}

\author{
Marta Ramona Novăceanu (Oprea)
}

\begin{abstract}
The mass-media sector re-comprises every day as a result of the constant and accelerated increase of new technologies. Among the new media, a spectacular evolution has been recorded lately by the podcast. The most recent research (Digital News Report, 2019), show that more and more audience leave the traditional radio in favour of new technologies, such as podcast, streaming or on-line radio, means that continue to make a revolution in the actual media environment. We could say that podcasting is a transition from the traditional radio to the customised radio, upon request (à la carte) and that this new media instrument varies from the programes produced ta home by podcasters that are not journalists to the specialised radio broadcast. We introduced this opposition between the two figures, the one of the expert and the one of the amateur, in order to see if the context of the multitude of podcasts that exist on the market, from the most professional to the ones created by amateurs, differences exist and of what nature these differences are. It is in fact, the purpose of this article, that shall focus on a comparative assessment between the podcast proposed by professionals and the one proposed by amateurs in Romania and France. Consequently, in this paper $I$ intend to examine podcasting from a production perspective, focusing on the similarities and differences between radio and podcasting as a way of delivering audio content.
\end{abstract}

Index Terms - à la carte radio, mobility, podcast, traditional radio.

\section{INTRODUCTION}

Traditional radio has been challenged for more than a decade by emerging forms of electronic media that know no borders and have the capacity to empower the public to take control of information and entertainment from traditional keepers.

Recent research points out that more and more audiences are abandoning traditional radio in favour of new technologies and that the interest in podcasts is constantly growing [1-2].

Several attempts to understand the appearance of the podcast were made both theoretically and practically. They oscillate between "fascination and rejection" [3]. However, a deeper inspection of the podcasting boom is lacking or generally restricted to studies that primarily examine the history and uses of this new technology from the perspective of the audience [4-11]. Other research [12] has focused primarily on audiences, on the ones downloading podcasts, as well as on the motivations of the user.

Marta Ramona Novăceanu (Oprea), PhD Student, Faculty of Journalism and Communication Science/University of Bucharest/Bucharest/Romania
Consequently, in this research paper, I intend to analyse podcasting from the production perspective, with a focus on the similarities and differences between radio and native podcasts and between amateur, independent and professional podcasters.

\section{METHODOLOGY}

The research paper shall focus on a comparative analysis between the podcast offer proposed by professionals (radio journalists) and the one proposed by independent and amateur podcasters from Romania and France. This relationship between the two types of podcasts seems all the more justified as there is a continuous growth of amateur content creators, which increasingly represent an alternative to traditional radio.

I chose to focus on these two podcasting markets in Romania and France, firstly because in Romania, until now (2020) no research has been conducted in the field of podcasting, and secondly because most of the research worldwide has so far been limited to the podcast industry from the United States of America or to a group of English-speaking countries, as evidenced by the report of the Reuters Institute - News Podcasting and the Opportunities for Publishers (2019).

The report also shows that after the United States of America, Brazil is the second largest podcasting market in the world, and France is also experiencing a significant increase in audience and independent podcast studios.

When I started my research, I had several questions in mind: how does podcasting change conventional radio formats? which are the podcast producers' methods of approach towards users? how will traditional journalists adapt to the new media? does the podcast create new forms of connections, groups or social spaces?

Based on these, I formulated four main research questions:

- Does podcasting only offer a different technological possibility (convergence), or rather a completely new approach to the idea of radio - of interactivity, intimacy, flexibility, and so on? Can podcasting be considered a new radio or is it rather a linear extension of an existing media technology - the traditional radio?

- How does the podcast change the relationship between traditional radio and this new audio format? What does podcasting improve?

- Are there significant differences between radio podcasts and native podcasts? But between podcasts created by professionals and those created by independent persons (amateurs)? 


\section{From The Traditional Radio to Podcast or To the À La Carte}

- Which are the challenges that occur as traditional radio journalists adopt the podcast in their practices? Can the traditional radio be adjusted?

In answering these questions, I would like to conduct a study for the analysis of podcast production in order to develop a perspective on this phenomenon in traditional radio as well as in independent podcast companies from Romania and France. In order to do so, I will use the in-depth interview as a method of qualitative research, with semi-structured questions.

\section{Corpus}

As it is difficult to identify all the podcasts on the network because they are numerous and constantly evolving, I chose to focus my observations on the most representative ones, according Top podcasts from top charts and podcast players around the world from Chartable.com (2019): Radio France, France Culture and native podcasts Slate, Louie Media, Binge Audio, Patrick Beja, host of RDV and BoxSons podcasts. A snapshot of the top 24 French podcasts in Apple Podcasts can be seen in Fig. 1 [13]: 16 of them are radio replay, 8 are native.

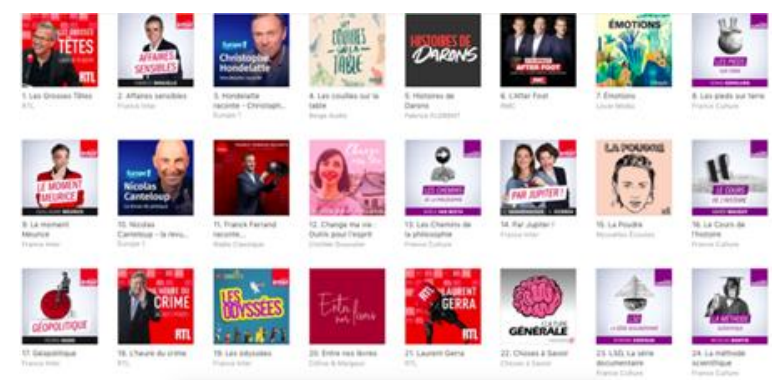

Fig. 1 - The top 24 French podcasts in Apple Podcasts

In Romania I focused my observations on the podcasts from Radio Romania, Radio Romania Cultural, Radio Guerrilla and on the native podcasts "Pe bune", made by Andreea Vrabie, "UPGRADE 100”, made by Dragoș Stanca, "IGDLCC - Gratis despre Lucruri care Costă", made by George Buhnici, Metope, made by Theodor Paleologu and "Podcastu' lui Katai", made by Robert Katai. A snapshot of the native podcasts from Romania can be seen in Fig. 2 [14] in the first network of podcasts in Romania - Thinkdigital Podcast Network.

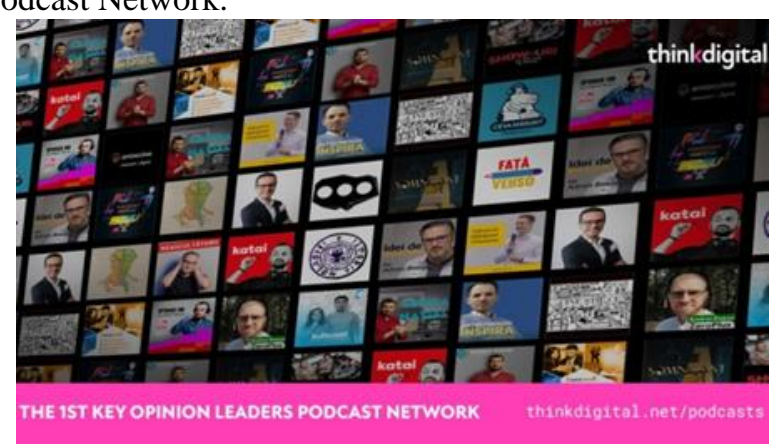

Fig. 2 Native podcasts from Romania

I conducted four semi-structured interviews with persons responsible for management within the two public radio stations in France and Romania (Radio France and Radio Romania), 10 interviews with persons in key positions developing innovative projects in the cultural and creative industries in Paris and Montpellier and with persons responsible for the improvement of audio automation products as well as 12 interviews with professional, independent and amateur podcast producers from the two countries.

This selection of companies allowed me to compare the markets and observe the differences between the podcast industry in the two countries. All interviewees have relevant experience, meaning that they supervise or work directly with podcasts or other audio products within their company. The interviews were conducted between January - April 2019 and April - June 2020. Eight of the interviews were conducted face to face, and the rest of them through Skype.

\section{LISTENERS CHANGE THE FREQUENCY. FROM FAST-RADIO TO À LA CARTE}

While most of the interviewees answering the question of whether podcasting can be considered radio or rather a linear extension of an existing media technology - the traditional radio? argue that native podcasting is different from radio, especially through the fact that it is no longer an ephemeral medium and could be defined as a support rather than media per se, I noticed that many persons in the cultural industries still consider that such a distinction is not necessarily beneficial to this new medium.

For instance, for Anthony Gourraud, innovation engineer within the Research-Innovation department of Mediameeting Company in Toulouse, a French Voice Business Company:

"There is not necessarily an opposition or distinctions to be made between radio and podcasting. The only difference in potential originates from technology. Everyone is free to offer and consume content posted online or to download audio content globally, not just locally. This is not applicable in radio (GO, FM, DAB+). Historically, the content delivery on-demand was not possible. The radio model (analogue broadcasting in GO, then the arrival of FM) always implied, through technical limitations, a continuous broadcast, with identical listening for all at a time $\mathrm{T}$, within the limits of a certain area. The idea is to supply an antenna, which emits a single audio stream that is attached to the listeners. This model was then transposed into digital, IP (web radio) as well as $\mathrm{DAB}+$ (Digital Audio Broadcasting). But IP allows for something that brings a revolutionary listening experience: the user is no longer constrained by the timing of content delivery, but has the ability to consume on-demand (whenever he/she wants, wherever he/she wants). But I still believe that in practice, podcasting is a new form of radio broadcasting; there is not something different. Rather, let's distinguish between broadcasting and podcasting. Keep in mind that the radio can play podcasts naturally, but not the other way around, due to technical, financial and even legal constraints (copyright, and so on".).

(Anthony Gourraud - innovation engineer within the Research-Innovation department of Mediameeting Company in Toulouse) 
Instead, according to Yves Bommenel, director of development within La coopérative illusion \& macadam, a company established in Montpellier that aims to support the development of the cultural and artistic sector, podcasting is rather a new support than new media.

"If the common point is the sound, the radio will remain connected to a continuous broadcasting mode. In my opinion, the podcast seems to be more related to the recorded media (cassette tapes, long-playing records, and so on), even if the recorded radio remains a radio, because a recorded concert remains a concert".

(Yves Bommenel - director of development within La cooperérative illusion \& macadam)

Also for Thibaud Delavigne - journalist and founder of the company L'officine in Paris, an organization that creates podcasts for the mass media or companies, from a technical point of view, the podcast is just a support to listen to the sound.

"Whether its use is to listen to radio programs again through frequency modulation (FM) or to listen to native podcasts, the technique is the same. It seems to me that the two uses are equal because it can often be the same audience. Replay consumers are also consumers of native creations. I don't want to be in opposition with them! "

\section{(Thibaud Delavigne - founder of L'offficine)}

For Bastien Nicolai, artistic director at Studio Podcast Montpellier, "the native podcast is media per se, while the replay podcast is an extension of the radio. The radio imposes its own programs, while the native podcast allows listeners to listen to their favourite programs and avoid unwanted information (even weather forecasts, if they are not interested in such information). The advantage of this medium is that you can say what you want on any subject; you can talk without taboo about deeper things and aspects that are less present in other media. While the radio is intended for a mass audience.

(Bastien Nicolai - artistic director at Studio Podcast Montpellier)

Sarah Toporoff, who conducts research on radio software users within NETIA company, closely working with Radio France users and having an international vision of the sector, including Romania, where she has collaborated with several independent media organizations such as the Center for Independent Journalism, the Republic, or the native podcast "Pe bune", made by Andreea Vrabie from "Decât o Revistă" magazine. In this context, she is particularly interested in how traditional radio fits into the growing and changing podcasting ecosystem. Sarah Toporoff observes that while French podcasting has entered adolescence, in Romania it is only in an early phase, it has just begun to outline. However it is "interesting that the radio podcast continues to dominate both podcast markets," claims Toporoff.
"It is worth noting that radio broadcasters are constantly the largest producers of podcasts, both in France and in Romania, - mainly due to the amount of replay materials they are able to provide. In France, 138 of the first 200 podcasts are podcasts taken from radio programs, but only about $5 \%$ of them are native. About $80 \%$ of the top internal podcasts are produced by the mainstream radio stations Radio France (France Culture, France Inter and France Info), RTL and Europe 1."

(Sarah Toporoff - Customer Workflow Specialist at NETIA Radio Software)

Radios are starting to expand their native podcast offering and are trying to take a different approach to their programming.

The director of France Culture, Sandrine Treiner, claims that:

"We are an on-demand radio. Whether that demand is for the scheduled broadcast or elsewhere."

Yet even native podcasts from Radio France are beholden to the ways of live radio. Every podcast from Radio France must be broadcast on the airwaves at some point, usually in the wee hours of the morning. This is so that the content may be entered into the existing framework for public radio for copyright, royalties and archiving. Radio France has existing agreements for broadcast with SACEM (Society of Authors, Composers and Publishers of Music) and SCAM (Civil Society of Multimedia Authors), but native on-demand content is a legal void.

Most of the independent podcasters I interviewed report significant differences between radio and native podcasts. This is also the case of Patrick Beja, an independent French podcaster, host of the Le RDV Tech podcast:

"More and more radio programs are being produced in order to be listened to in a podcast and broadcast on various audio streams, but most of them are nothing more than recoveries of shows that have already been broadcast on FM. Specifically, the content of these programs is not adapted to on-demand listening, although it would require only minor adjustments. Thus, not infrequently, the listener of a replay podcast can hear announcements about the program that will follow on the radio or even statements of the producer about the time (for example: 3 minutes past 12), which are completely irrelevant to someone who listens to a podcast".

\section{(Patrick Beja - host of the Le RDV Tech podcast)}

Regarding the differences between amateurs and professionals, most of the interviewees argue that the only difference would be that replay podcasts are too often designed and produced for the distribution in a linear (direct) stream.

"Amateur and professional productions can be found both on radio and in podcasts. There is not only one type of "radio format". In addition, there are several categories of radio (A, B, C, D, E, public service) and each station adopts more or less a "format" with or without an overall coherence of the antenna, as it could also do an "independent" podcast studio. 


\section{From The Traditional Radio to Podcast or To the À La Carte}

Remember that any "native podcast" (produced by an "independent" podcaster or not) could just as well be broadcast on the radio within a live show. Audio fiction has existed throughout the centuries in the French culture, "new writing" and other "stories on non-mainstream topics" (understanding minorities, niche topics, and so on) have always existed, especially in associative radios.

In this regard, most interviewees believe that traditional radios should ensure that they better package their productions so that the published content is appropriate for a non-linear, on-demand listening. It seems that more and more radio stations have understood that if a program does not have a strong connection to the live, it must first be produced for listening in the podcast, then integrated into the linear stream.

For Dragoș Stanca, digital media expert and producer of the "UPGRADE 100" podcast, "podcasting is radio in the same way that Netflix type video-on-demand is cinema or the livestream on Youtube or IGTV or Facebook Watch is TV; it is not radio, it is audio-on-demand, online."

On the other hand, like many other specialists in the cultural industries, Dragoș Stanca claims that this radio-podcast differentiation is increasingly irrelevant and believes that things should be simplified.

"Specifically, there are several forms of distribution of three major forms of content packaging: audio, static (photo) or dynamic (video) images and text. The way of distributing this content thus expressed is less and less important, in my opinion. Radio is just a format for distributing audio content, especially live. The podcast is just a format for distributing audio content, especially recorded. We call what we call radio nowadays, especially after the instrument intended for listening: the radio. As we use the word podcast to describe the audio content after the name of a device: the iPod. But this is becoming increasingly irrelevant these days, when what we were calling radio or what we call podcasts can be listened to on any smartphone - regardless of manufacturer - or via Alexa or Google Home."

(Dragoș Stanca - managing partner TDG - Think Digital Group of companies (in Romania) and president of BRAT Romanian Transmedia Audit Bureau).

Dragoș Stanca considers that the challenge, in the area of monetizing podcasts that are not based on world languages, is the monetization.

"In the case of digital audio content, there is not even a Youtube or equivalent product that can do this professional activity and not just as a hobby. I say "not even", because Youtube pays badly a creator from Romania (and from other small countries). Spotify, Apple or Google Podcasts do not pay for content in countries like Romania yet, but only offer the distribution platform. If in the world of traditional digital advertising there are now several forms of monetization: special projects, direct negotiation, automated direct advertising or via open ad exchanges (Google AdSense type), in the case of podcasts there is no dedicated technology to automate the audio-advertising transaction located on restricted languages ".
(Dragoș Stanca - managing partner TDG - Think Digital Group of companies (in Romania) and president of BRAT Romanian Transmedia Audit Bureau).

The Romanian podcaster George Buhnici also thinks that podcasting, like radio, is just media support.

"Podcasting is more like radio than is vlogging similar to television, but through the audio format, first of all, which requires structure and quality. Technology offers the possibility for a podcast to travel anywhere and on any support that can play audio, not only where there is a radio signal, even beyond the limits of the Internet and electricity, and that makes it much stronger. The spoken word remains valuable, and technology now amplifies it better than ever. But both the podcast and the radio remain just technologies for transporting ideas from the creator to the audience."

(George Buhnici - Leading tech-voice in Romania, author of the "IGDLCC" podcast - Informație Gratis despre Lucruri care Costă)

\section{CONCLUSIONS}

Therefore, it remains legitimate the definition of the radio through its programs and media content, rather than through the imperfections of wireless transmission; there is a clear distinction between the capture of a signal by the analogue and digital radio. However, the reception of the web radio remains quite close to that of the FM network, the broadcast being subject to the stream logic.

But this is not the case with podcasts, where the relation between broadcast sender and receiver is different. Because the expression here and now in the sense of live, fast-radio, is no longer characteristic to podcasts. In contrast to the radio, the podcast is not speed-dependent and syncs with the listener. Moreover, this type of broadcasting is no longer ephemeral, but remains, materializes, and can be archived. It becomes a concrete object that can be interrupted by the listener and listened to whenever he/she wants.

The mass media is no longer recorded in the stream, but on the contrary, in a logical storage.

The act of reception becomes decisive; the listener himself/herself chooses the place and time when he/she listens to a program, not mass media. This is what the podcast allows, as it breaks the traditional stream of radio. In addition, it allows the broadcasting of sound through an autonomous approach of the listeners, who will download certain audio files or subscribe to them and thus will benefit from updated access to the contents that interest them.

Therefore, reconfigured around these features, the podcast seems like a very expressive form of communication and not a classic means of communication, although both podcasts and radio represent an auditory experience.

We could say that the podcast is rather a transition from traditional radio, from fast-radio, to personalized, à la carte one and also a collaborative medium, where producers work independently.

From one-day listeners, they become the podcasters of the next day, full-fledged publishers who participate in the development and broadcasting of content in the same way as 
the mass media.

The digitization of radio has been a major challenge in terms of production, distribution and consumption methods, but now, more than ever, its evolution and future are going through new technologies that promote listening mobility (new DAB + services, connected machines, voice assistants etc.).

Although traditional radio has largely managed to adapt to this new technology, it has so far failed to recapture that young audience migrating to new media such as the podcast, as evidenced by the latest audience research. And I think that's the challenge of traditional radio for now. To find the means necessary to reach and / or recover this public. And for traditional radio to fully integrate into this ecosystem, a change in production is needed.

Therefore, it is necessary for radio operators to think in digital terms the whole medium of distribution and consumption of sound content. Starting with connected speakers, applications and audio streaming platforms.

I think that is actually the survival of the traditional radio. The provision of audio content on different channels, respectively the necessity of rethinking new digital uses.

\section{ACKNOWLEDGMENT}

Writing this paper was possible due to financial support provided by „Entrepreneurial Education and Professional Counseling for Social and Human Sciences $\mathrm{PhD}$ and Postdoctoral Researchers to ensure knowledge transfer from the field of Social Sciences and Humanities to the Labor Market" Project, co-financed from European Social Fund through Human Capital Programme (ATRiUM, POCU/380/6/13/123343).

\section{REFERENCES}

[1] Newman N.\&Gallo N.,News Podcasts and the Opportunities for Publishers. $\quad$ Retrieved from: http://www.digitalnewsreport.org/publications/2019/news-podcasts-op portunities-publishers/, 2019.

[2] The podcast consumer 2019, research published on April 5, 2019, available https://www.edisonresearch.com/the-podcast-consumer-2019/, accessed on 03.06.2020

[3] Krebs C., Radio, entre approches critiques, théoriques, expérimentales". Recherches sur la radio dans quelques pays européens, 2008, Berlin : Editions Avinus Verlag, available at http://www.grer.fr/biblio.php?cat=publications\&id=1235\&mod=1.

[4] Berry, R., Podcasting: Considering the evolution of the medium and its association with the word radio. The Radio Journal-International Studies in Broadcast \& Audio Media, 14, 7-22. doi:10.1386/rjao.14.1.7_1, 2016.

[5] Bottomley, A. J., Podcasting: A decade in the life of a "new" audio medium: Introduction. Journal of Radio \& Audio Media, 22, 164-169. doi:10.1080/19376529.2015.1082880, 2015.

[6] Cwynar, C. , More than a "VCR for radio": The CBC, the Radio 3 Podcast, and the uses of an emerging medium. Journal of Radio \& Audio Media, 22, 190-199. doi:10.1080/, 2015.

[7] Lindgren, M., Personal narrative journalism and podcasting. The Radio Journal-International Studies in Broadcast \& Audio Media, 14, 23-41. doi:10.1386/rjao.14.1.23_1, 2016.

[8] McHugh, S., How podcasting is changing the audio storytelling genre. The Radio Journal-International Studies in Broadcast \& Audio Media, 14, 65-82. doi:10.1386/rjao.14.1.65_1 [Crossref], [Google Scholar], 2016.

[9] Markman, K. M, Everything old is new again: Podcasting as radio's revival. Journal of Radio \& Audio Media, 22, 240-243. doi:10.1080/19376529.2015.1083376, 2015.
[10] [Mou, Y., \& Lin, C. A., Exploring podcast adoption intention via perceived social norms, interpersonal communication, and theory of planned behavior. Journal of Broadcasting \& Electronic Media, 59, 475-493. doi:10.1080/08838151.2015.1054997, 2015.

[11] Wrather, K., Making "maximum fun" for fans: Examining podcast listener participation online. The Radio Journal-International Studies in Broadcast \& Audio Media, 14, 43-63, 2016.

[12] Boling K. S. \& Hull K, Undisclosed Information-Serial Is My Favorite Murder: Examining Motivations in the True Crime Podcast Audience, Journal of Radio \& Audio Media, 25:1, 92-108, DOI: 10.1080/19376529.2017.1370714, 2018.

[13] Podcast Charts Apple Podcasts - France - All Podcasts. Retrieved from: https://chartable.com/charts/itunes/fr-all-podcasts-podcasts, 2020.

[14] The $1^{\text {st }}$ key opinion leaders podcast network in Romania. Retrieved from: https://www.thinkdigital.net/podcasts/, 2020. 